OPEN ACCESS

Edited by:

Yuji Morita,

Aichi Gakuin University, Japan

Reviewed by:

Osmar Nascimento Silva,

Dom Bosco Catholic University, Brazil

J. Fernando Ayala-Zavala,

Centro de Investigación en

Alimentación y Desarrollo, Mexico

*Correspondence: Nitin Mantr

nitin.mantri@rmit.edu.au

Specialty section:

This article was submitted to Antimicrobials, Resistance

and Chemotherapy,

a section of the journal

Frontiers in Microbiology

Received: 03 March 2016 Accepted: 26 April 2016

Published: 17 May 2016

Citation:

Yamani HA, Pang EC, MantriN and Deighton MA (2016) Antimicrobial Activity of Tulsi (Ocimum tenuiflorum)

Essential Oil and Their Major Constituents against Three Species of Bacteria. Front. Microbiol. 7:681. doi: 10.3389/fmicb.2016.00681

\section{Antimicrobial Activity of Tulsi (Ocimum tenuiflorum) Essential Oil and Their Major Constituents against Three Species of Bacteria}

\author{
Hanaa A. Yamani1,2, Edwin C. Pang ${ }^{1}$, Nitin Mantri ${ }^{1 *}$ and Margaret A. Deighton ${ }^{1}$ \\ ${ }^{1}$ School of Science, Royal Melbourne Institute of Technology University, Melbourne, VIC, Australia, ${ }^{2}$ Biology, Section \\ Microbiology, School of Applied Sciences, King Abdulaziz University, Jeddah, Saudi Arabia
}

In recent years scientists worldwide have realized that the effective life span of any antimicrobial agent is limited, due to increasing development of resistance by microorganisms. Consequently, numerous studies have been conducted to find new alternative sources of antimicrobial agents, especially from plants. The aims of this project were to examine the antimicrobial properties of essential oils distilled from Australian-grown Ocimum tenuiflorum (Tulsi), to quantify the volatile components present in flower spikes, leaves and the essential oil, and to investigate the compounds responsible for any activity. Broth micro-dilution was used to determine the minimum inhibitory concentration (MIC) of Tulsi essential oil against selected microbial pathogens. The oils, at concentrations of 4.5 and $2.25 \%$ completely inhibited the growth of Staphylococcus aureus (including MRSA) and Escherichia coli, while the same concentrations only partly inhibited the growth of Pseudomonas aeruginosa. Of 54 compounds identified in Tulsi leaves, flower spikes, or essential oil, three are proposed to be responsible for this activity; camphor, eucalyptol and eugenol. Since S. aureus (including MRSA), P. aeruginosa and $E$. coli are major pathogens causing skin and soft tissue infections, Tulsi essential oil could be a valuable topical antimicrobial agent for management of skin infections caused by these organisms.

Keywords: Tulsi (Ocimum tenuiflorum), essential oil, antimicrobial activity, headspace-solid phase microextraction, gas chromatography-mass spectrometry

\section{INTRODUCTION}

The use of medicinal plants in traditional medicine has been described in literature dating back several 1000 years (Chang et al., 2016). Books on Ayurvedic medicine, written in the Vedic period (3500-1600 B.C.) describe practices, including the use of medicinal plants, that formed the basis of all other medical sciences developed on the Indian subcontinent (Pattanayak et al., 2010). In modern complementary and alternative medical practice, plants are the primary source of therapeutics and each part of the plant, including the seeds, root, stem, leaves, and fruit, potentially contains bioactive components (Jiang et al., 2014, 2015; Mandave et al., 2014; Sun et al., 2014). The main bioactive components in medicinal plants are considered to be combinations of secondary metabolites (Singh et al., 2010; Wu et al., 2016). There are many advantages and benefits associated with the use of medicinal plants, the main ones being their cost-effectiveness and global availability. 
Their safety compared to other medicinal products and the lack of major side-effects are other clear advantages (Niu et al., 2011). However, plant metabolism is very variable and before medicinal plant extracts or products are approved for primary health care, they need to be standardized, subjected to stringent quality control and assessed to ensure their safety (Mantri et al., 2012; Olarte et al., 2013).

Among the medicinal plants, aromatic herbs are a rich source of biologically active compounds useful both in agriculture and medicine (Mathela, 1991; Cutler and Cutler, 1999). Of these, Ocimum tenuiflorum, also known as Ocimum sanctum, Tulsi, or Holy Basil from the family Lamiaceae has been described as the "Queen of plants" and the "mother medicine of nature" due to its perceived medicinal qualities (Singh et al., 2010). It has been one of the most valued and holistic herbs used over years in traditional medicine in India and almost every part of the plant has been found to possess therapeutic properties (Singh et al., 2010). Traditionally, Tulsi is used in different forms; aqueous extracts from the leaves (fresh or dried as powder) are used in herbal teas or mixed with other herbs or honey to enhance the medicinal value. Traditional uses of Tulsi aqueous extracts include the treatment of different types of poisoning, stomach-ache, common colds, headaches, malaria, inflammation, and heart disease (Pattanayak et al., 2010). Oils extracted from the leaves and inflorescence of Tulsi have been claimed to have numerous useful properties, including as expectorants, analgesics, anti-emetics, and antipyretics; stress reducers and inflammation relievers; and as anti-asthmatic, hypoglycemic, hepatoprotective, hypotensive, hypolipidemic, and immunomodulatory agents (Singh et al., 2010).

Several scientists have examined pharmacological effects of Tulsi products obtained by different extraction methods, such as steam distillation, benzene extraction and petroleum extraction. Prakash and Gupta (2005), reviewed all the scientific studies of the therapeutic significance of Tulsi and eugenol, a major component of Tulsi. These pharmacological studies may be helpful to establish a scientific basis for the therapeutic use of this plant, especially in regard to the pharmacological effect on the central nervous system, immune system, cardiovascular system, reproductive system, and the gastric and urinary systems.

Skin and soft tissue infections (SSTIs) are the cause considerable morbidity and cost to the community. Major causes of these infections are Staphylococcus aureus, Pseudomonas aeruginosa, and Escherichia coli and SENTRY Antimicrobial Surveillance Program, 2009 (Dryden, 2009, 2010). Although infections are often mild or moderate in severity, severe cases may require hospitalization and treatment with oral or parenteral antimicrobial agents. For instance, in 1995 more than 43,000 patients required hospitalized for treatment of SSTI in Scotland and 300,000 in the US (Eron et al., 2003). In recent years, SSTIs have become more difficult to manage due to the increasing occurrence of multidrug-resistant pathogens. To avoid the expansion of multidrug-resistant pathogens clinically, it is essential to differentiate between SSTI which require antibiotic treatment and those that do not. A recent survey in Europe reported that a major percentage of physicians prescribe systemic antibiotics for the treatment of conditions, such as MRSAcolonized ulcers or broken skin surfaces, that do require systemic antibiotics (Dryden, 2010). Essential oil or its components may be valuable agents for the treatment of mild or moderate skin infections or colonized ulcers, preventing progression to more serious infections and minimizing the unnecessary antibiotic use and the associated development of resistance.

The aims of this study were to (i) examine the antimicrobial properties of Tulsi essential oil, (ii) analyze the volatile composition of leaves, flower spikes, and extracted oil from Tulsi plants grown in Australia using headspace-solid phase microextraction-gas chromatography-mass spectrometry (HSSPME-GC-MS), and (iii) after reviewing the literature, suggest which volatile compounds are most likely to be responsible for the antimicrobial activity of Tulsi oil. To the best of our knowledge this is the first analysis the Australian-grown fresh Tulsi flowers spikes, leaves, and the essential oil extracted from flowers and leaves using HS-SPME-GC-MS.

\section{MATERIALS AND METHODS}

\section{Source of Tulsi}

Tulsi (Ocimum tenuiflorum), Voucher number PHARM-14-0028 obtained from the Medicinal Plant Herbarium at Southern Cross University, NSW, Australia, was used in this experiment. Fresh leaves and inflorescence $(350 \mathrm{gm})$ were steam-distilled for $6 \mathrm{~h}$ in an essential oil Steam Distiller (Modified Clevenger apparatus) (Steam Distillation Apparatus, Crucible, Sacramento, CA, USA). The yield of volatile oil (weight of oil/weight of leaves made into a percentage) obtained was $0.57 \% \mathrm{v} / \mathrm{w}$. The yellow colored volatile oil was stored in a sealed container at $<4^{\circ} \mathrm{C}$ in the dark until needed.

\section{Antimicrobial Activity of Tulsi Essential Oil}

The bacterial strains used in this study were $S$. aureus ATCC 25923, clinical isolate of methicillin-resistant $S$. aureus (MRSA) NCTC 6571 "Oxford Strain”, E. coli ATCC 25922 and P. aeruginosa ATCC 27853.

The extracted oil was emulsified in Mueller-Hinton Broth (MHB, Oxoid, Adelaide, SA, Australia) by the following method: $90 \mu \mathrm{l}$ of the essential oil and $10 \mu \mathrm{l}$ of DMSO were added to a sterile Eppendorf tube (Sarstedt, Technology Park, SA, Australia). The solution was mixed by vortexing then $900 \mu \mathrm{l}$ of the MHB was added in $30 \mu \mathrm{L}$ aliquots, with brief vortexing between each addition. The broth dilution method was used to determine the minimal inhibitory concentration (MIC) of the Tulsi essential oil for each bacterial species (Wiegand et al., 2008). Two-fold dilutions of essential oil, diluted, and solubilized as described above, beginning at $9 \%$ (undiluted), in volumes of $50 \mu \mathrm{l}$ were prepared in MHB in a 96-well sterile flat bottomed microtiter plate (Corning, Hickory, USA), then $50 \mu \mathrm{l}$ of bacterial suspension was added to each well, such that the final concentration was $5 \times 10^{5} \mathrm{cfu}$ in each well. The oil mixture was further diluted in the test $(1: 2)$ by the bacterial suspension, resulting in a solution containing of $4.5 \%$ essential oil in the first well. Plates 
were incubated for $24 \mathrm{~h}$ at $37^{\circ} \mathrm{C}$ in the dark on an orbital shaker at $100 \mathrm{rpm}$ to prevent adherence and clumping. After incubation, the optical density of the contents of each well was determined using a spectrophotometer at $620 \mathrm{~nm}$ (Omega BMG LabTech, Ortenberg, Germany). For the minimal bactericidal concentration (MBC), $100 \mu \mathrm{l}$ aliquots from each well were plated onto MHB agar and viable counts were determined after incubation for $24 \mathrm{~h}$ at $37^{\circ} \mathrm{C}$ (Clinical and Laboratory Standards Institute, 2012).

IBM SPSS (Statistical Package for the Social Sciences) (v.22, IBM Corporation, New York, NY, USA) was used for the statistical analysis of the amount of bacterial growth when treated with different concentrations of Tulsi essential oil. An alpha level of 0.05 was assumed for the determination of statistical significance. Analysis of variance (ANOVA) was followed by post hoc Tukey test to compare the amount of bacterial growth in wells containing different concentrations of essential oil. Data was calculated from two different experiments each conducted in triplicate.

\section{Isolation and Identification of Volatile Compounds from Leaves, Flower Spikes, and Oil}

Fresh leaves, and flower spikes of Tulsi Ocimum tenuiflorum from the same source as the essential oil (distilled as described above) were collected from the Chinese medicinal garden at RMIT University, Bundoora Campus (Melbourne, VIC, Australia) in the summer of 2012; the temperature range during the growing season was $22-35^{\circ} \mathrm{C}$. The samples were kept on ice after collection and during transportation to the laboratory, where $0.15 \mathrm{~g}$ of the inflorescence, fresh leaf material ground in a mortar and pestle unit, or essential oil was placed in a 4-ml clear, screwtop vial and sealed with a black polypropylene open-top cap and a PTFE (polytetrafluoroethylene)/silicone septum (Agilent Technologies, Santa Clara, CA, USA) and used immediately.

\section{Extraction of Volatile Compounds by HS-SPME}

Extraction of the volatile compounds from the ground leaf material, flower spikes and oil was performed by headspace-solid phase micro-extraction (HS-SPME) using modified protocol of Yamani et al. (2014). A 85- $\mu \mathrm{m}$ polyacrylate (PA) fiber fitted to a manual sampling fiber holder (Supelco, Bellefonte, PA, USA) was conditioned according to the manufacturer's instructions by placing into the gas chromatograph (GC) injection port at $250^{\circ} \mathrm{C}$ for $30 \mathrm{~min}$ before use. The preconditioned PA fiber was allowed to cool then inserted into the headspace of the vial containing the sample, and then the whole system was placed in a heating block at $40^{\circ} \mathrm{C}$ for $50 \mathrm{~min}$. The volatiles were then desorbed by placing the fiber in the GC injection port for $5 \mathrm{~min}$. The equilibrium time profile was developed using the method of Da Porto and Decorti (2008) with slight modifications; vials were placed in the heating block at $40^{\circ} \mathrm{C}$ instead of $30^{\circ} \mathrm{C}$ in order to extract all the compounds that might be present under hot conditions on summer days in Melbourne. Moreover, heating at $40^{\circ} \mathrm{C}$ resulted in an increased amount of volatile compounds on the fiber and a higher number of resulting peaks compared to heating at $30^{\circ} \mathrm{C}$.

\section{Gas Chromatography-Mass Spectrometry}

Identification of the volatile compounds from leaves, flower spikes and oil was performed using an Agilent 5973 GC hyphenated mass spectrometer (MS) system fitted with a DB5 MS (5\%-phenyl)-methylpolysiloxane fused silica column with dimensions $30 \mathrm{~m} \times 250 \mu \mathrm{m}$, i.e., film thickness $0.25 \mu \mathrm{m}$, (Agilent Technologies, Mulgrave, VIC, Australia). Helium (99.99\% purity) was used as the carrier gas at a flow rate of $1.5 \mathrm{ml} / \mathrm{min}$. The split ratio was 50:1. The initial GC oven temperature was $40^{\circ} \mathrm{C}$ for $3 \mathrm{~min}$, after which it was raised from 40 to $250^{\circ} \mathrm{C}$ at $6^{\circ} \mathrm{C} / \mathrm{min}$, where it was held for $5 \mathrm{~min}$. The injection port, transfer line, and source temperatures were 250,280 , and $230^{\circ} \mathrm{C}$, respectively. The mass scan range was $41-415 \mathrm{~m} / \mathrm{z}$. Data acquisition and processing were performed using MSD ChemStation (E02.00.493) (Agilent Technologies, Mulgrave, VIC, Australia). Qualitative identification was performed using GC-MS reference libraries (Adams 2007, Wiley 7th edition, and NIST 2.0) using a $80 \%$ similarity match cut off value. Concentrations of the studied compounds were calculated from the peak areas in the total ion chromatograms. The relative abundance of each compound was obtained from electronic integration measurements using the mean of three replicates. Kovats standard retention indices were determined from the retention times of a series of $n$-alkane mixture analyzed under identical conditions.

\section{Cytotoxicity Testing}

The cytotoxicity of the tulsi extract toward HepG2 human cells was measured using Presto-blue ${ }^{\circledR}$ Cell Viability Reagent kit (number A13262). HepG2 cells were seeded at $4 \times 10^{4} /$ well on a 96-well plate in $100 \mu \mathrm{L}$ of growth medium and incubated for $24 \mathrm{~h}$ at $37^{\circ} \mathrm{C}$. The medium was then removed, and the cells were washed with phosphate buffered saline (PBS). Samples were diluted in treatment medium (WME supplemented with $2 \mathrm{mM}$ l-glutamine and $10 \mathrm{mM}$ HEPES) and $100 \mu \mathrm{L}$ of the samples were applied to the cells, then the plates were incubated at $37^{\circ} \mathrm{C}$ for $1 \mathrm{~h}$. The treatment medium was removed, and the cells were washed with PBS. PrestoBlue reagent was directly added to cells in culture medium (96-well plate $90 \mu \mathrm{L} 10 \mu \mathrm{L}$ ) and cells were incubated for $1-2 \mathrm{~h}$ at $37^{\circ} \mathrm{C}$. The absorbance at $570 \mathrm{~nm}$ was determined using spectrophotometer (Omega BMG LabTech, Ortenberg, Germany).

\section{RESULTS}

\section{The Antimicrobial Activity of Tulsi Essential Oil}

Tulsi oil at concentrations of 4.5 and $2.25 \%$ completely inhibited the growth of $S$. aureus, including MRSA and E. coli, while the same concentrations only partly inhibited the growth of $P$. aeruginosa (Figure 1). The MBC results showed that Tulsi 


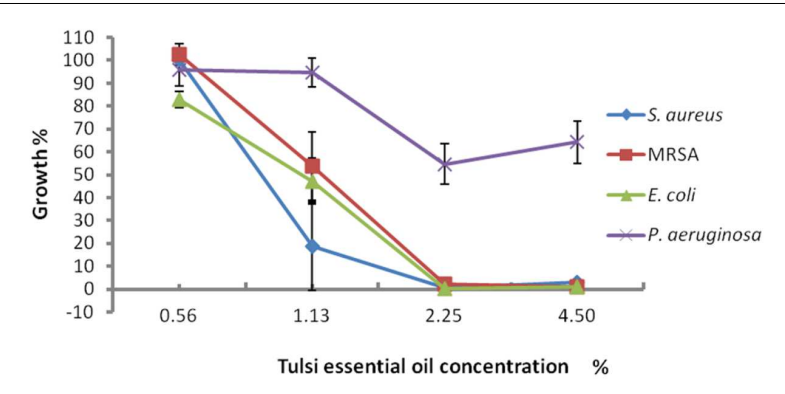

FIGURE 1 | The antimicrobial effect of different concentrations of Tulsi essential oil on the growth rate of four bacterial strains.

essential oil had only bacteriostatic activity against the examined bacterial strains. Viable bacterial counts were not measured because the plates were confluent indicating bacteriostatic activity. Statistical analysis of the spectrophotometric results showed that both the concentration of Tulsi oil and bacterial species used significantly affected the amount of growth $(P<0.05)$ (Table 1). The percentage of bacterial growth was lower overall when bacteria were treated with Tulsi oil at a concentration of $4.50 \%(17.29)$ and $2.23 \%$ (15.07) in comparison to $1.13 \%$ concentration (56.62). The main effect on the bacterial species growth for all essential oil concentrations was significant as well. The percentage of bacterial growth was lower for S. aureus (13.03), MRSA (18.58), and E. coli (17.99) than for $P$. aeruginosa (68.78). Overall, $P$. aeruginosa showed higher resistance to the antibacterial treatment with Tulsi oil, compared to three other bacteria used in the test. On the other hand, the mean difference of the percentage of bacterial growth between $S$. aureus, MRSA and E. coli was not significant $p>0.05$.

\section{Tulsi Volatile Composition}

The analysis of the Tulsi leaves, inflorescence and essential oil by HS-SPME and GC/MS resulted in the identification of 54 volatile components (Table 2). The most abundant of the volatile components were monoterpenes and sesquiterpenes; in particular monoterpenes such as camphor, cineole, estragol, and eugenol, followed by sesquiterpenes, such as germacrene, caryophyllene, bisabolene. Nineteen major compounds were present in all samples from all parts of the plant, but at different concentrations. Overall, there were no major differences between the presence of the most prevalent volatile

TABLE 1 | Analysis of variance (ANOVA) main effect of independent variables: tests of between-subjects effects.

\begin{tabular}{lccc}
\hline $\begin{array}{l}\text { Bacterial growth (\%) } \\
\text { (Dependent variable) }\end{array}$ & & \multicolumn{2}{c}{$\begin{array}{c}\text { Tests of Between-Subjects } \\
\text { Effects }\end{array}$} \\
\cline { 1 - 1 } \cline { 3 - 3 } Independent variable & & $F$ & Significance \\
\hline Concentration & 28.300 & 0.000 \\
Bacteria & 29.502 & 0.000 \\
Replicate & 2.423 & 0.126
\end{tabular}

compounds identified from the leaves, inflorescence, and the essential oil, but minor compounds were frequently identified in only one or more sample types. The most common compound detected was camphor, with slightly different concentrations in the essential oil (31.5\%), leaves (24.2\%), and inflorescence (22.6\%). This was followed by eucalyptol with higher concentration in both essential oil and leaves (18.9 and $13.47 \%$, respectively) than in the inflorescence (1.2\%). The third most commonly identified compound was eugenol that comprised $23.7 \%$ of the total volatile compounds in the leaves, $13.8 \%$ in the essential oil and $7.5 \%$ in inflorescence.

Similar to the present study, Medina-Holguín et al. (2007) reported that the volatile compounds from fresh plant material displayed different compositions from those of the essential oil extracted from the same plants. Therefore, it is informative to compare the proportions of the different volatile compounds in different parts of the plant. Monoterpenes, especially eugenol, and estragole were present in the highest amounts in the leaves (23.7 and 9.6\%, respectively), while sesquiterpenes ocimene (9.30\%), caryophyllene- $\beta$ (4.9\%), bergamotene $(2.8 \%)$, germacrene $(11.3 \%)$, beta bisabolene, $(10.7 \%)$, and alpha bisabolene $(16.7 \%)$ were more prevalent in the inflorescence. Conversely, some volatile compounds were absent from the oil and detected only in the leaves or inflorescence but in trace amounts $(<1 \%)$ at each site.

\section{Cytotoxicity Test}

The cytotoxicity of the extracts decreased in relation to decreasing concentration. The cell viability decreased by less than $20 \%$ when the cells were treated with a concentration of $20 \mathrm{mg} / \mathrm{ml}$. Both essential oil and concentrated leaf extract concentrations of $20 \mathrm{mg} / \mathrm{ml}$ were within the expected range as this concentration led to decreased cell viability by less than $20 \%$ and therefore were not considered cytotoxic. Concentrations below $20 \mathrm{mg} / \mathrm{ml}$ had no effect on the cell viability results, as shown in Figure 2.

\section{DISCUSSION}

\section{The Antimicrobial Activity of Tulsi Essential Oil}

The agar diffusion method (well or paper disk) and the dilution method (liquid broth or agar) are the two basic techniques used for the examination of the antimicrobial activity of the essential oils. Of these, the agar diffusion method was commonly used in earlier studies. This method requires only a small quantity of the essential oil and is easy to implement. However, it is considered inappropriate for the essential oil examination for two reasons. Firstly, essential oil is comprised of volatile compounds that are likely to evaporate from disks during the incubation time. Moreover, due to the low solubility of essential oils in agar, volatile compounds may not diffuse well. Recently, the broth dilution method using 96 well flat-bottom microtitre 
TABLE 2 | Volatile compounds extracted from flower spikes, flower with nectar, and leaves of Tulsi using HS-SPME/GC-MS.

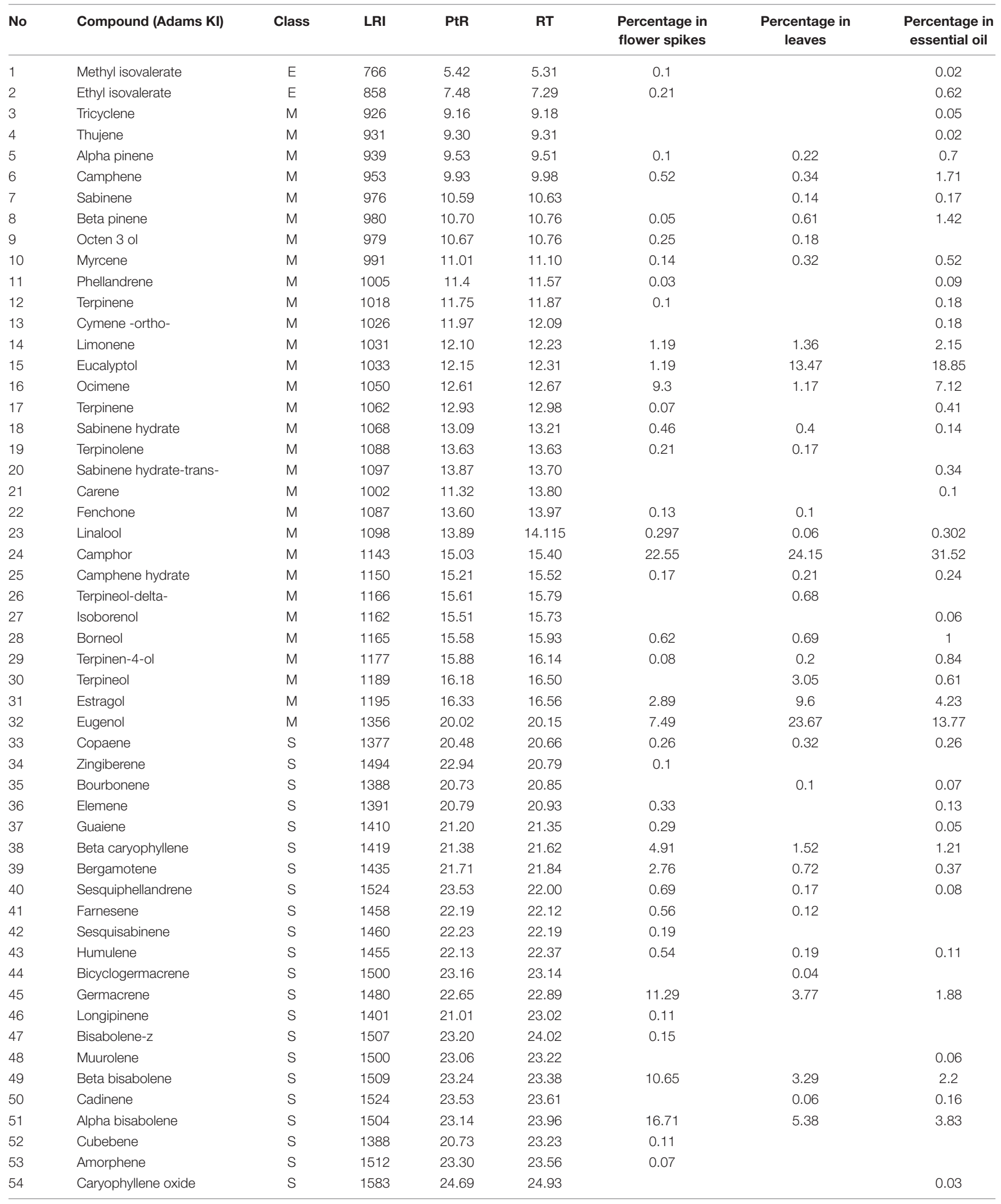

Blank spaces indicate a zero reading. Results show the average of three replicates. LRI - Linear retention index; PtR - Predicted retention time; E - Ester, $M$ Monoterpenes, S - Sesquiterpenes. 


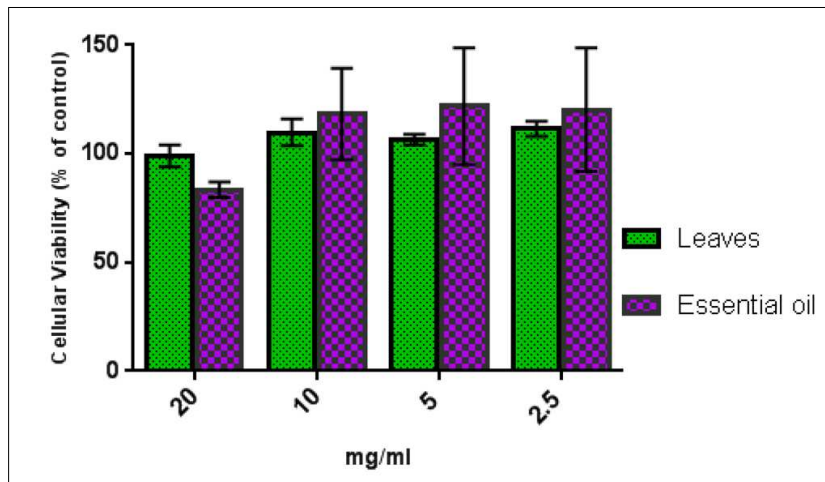

FIGURE 2 | Cell viability assay results of Tulsi essential oil and leaves extract.

plates has become the method of choice for determining the antimicrobial activity of essential oils. The activity of the essential oil is expressed as MIC and MBC. Kalemba and Kunicka (2003) strongly recommended that only MIC and MBC values should be published to facilitate comparisons between the results of different studies.

Our results show bacteriostatic activity of Tulsi oil at levels of 2.25-2.5 $\mu \mathrm{g} / \mathrm{ml}$ against S. aureus, including MRSA and E. coli, but less activity against $P$. aeruginosa (Table 3; Figure 1). These results are broadly similar to those of studies that used disk diffusion or optical density reduction methods; however, there are differences in reported activity toward Gram positive and Gram negative bacteria (Mahmood et al., 2008; Helen et al., 2011; Mishra and Mishra, 2011) (Table 3). Mahmood et al. (2008), using a disk diffusion assay obtained zones of inhibition around both Gram-positive and Gram-negative species, but activity was better against $S$. aureus than against Gram-negative species. Mishra and Mishra (2011) reported good inhibition of both Gram-positive and Gram-negative species, indicated by a reduction in optical density; however, $P$. aeruginosa showed slightly better activity under these test conditions than $S$. aureus. Interestingly, Tulsi essential oil from one subspecies of O. tenuiflorum was more effective against $P$. vulgaris, $S$. aureus, $P$. aeruginosa, and $E$. coli than extracts from two other Tulsi subspecies (Helen et al., 2011). These reported differences in the antimicrobial activity of Tulsi oil could relate to the specific composition of the volatile compounds in the oil, determined by the geographical source of the plants or specific cultivar. Other reasons for the differing results could be methodology used for determining antimicrobial activity. It is also worth noting that $P$. aeruginosa is well known for both intrinsic and acquired resistance to many classes of antimicrobial agents (Poole, 2011). Studies using other essential oils also reported variable results, depending on the oil and analytical method selected. Prabuseenivasan et al. (2006), using the agar dilution method demonstrated variable antibacterial activity of 21 essential oils against a range of Gram-positive and Gram-negative bacteria. Several investigators reported that Gram-positive bacteria are more sensitive to essential oils in general than Gram-negative bacteria (Burt, 2004). For example, S. aureus was suggested to be inhibited by using the synergies of oregano and rosemary essential oils or carvacrol and 1,8-cineole (Honório et al., 2015).

\section{Cytotoxicity Test}

The effect of Tulsi extract and essential oil on cell viability was determined using the Presto-Blue test. The cells were treated with different concentrations of the extract, ranging from 2.5 to $20 \mathrm{mg} / \mathrm{ml}$, and the results demonstrated that the cytotoxicity of the extracts decreased in relation to decreasing concentration. The cell viability decreased by less than $20 \%$ when the cells were treated with a concentration of $20 \mathrm{mg} / \mathrm{ml}$. Both essential oil and concentrated leaf extract concentrations of $20 \mathrm{mg} / \mathrm{ml}$ were within the expected range as these concentrations led to decreased cell viability by less than $20 \%$ and therefore were not considered cytotoxic.

TABLE 3 | Antibacterial activity of Ocimum sanctum (Tulsi) essential oil.

\begin{tabular}{|c|c|c|c|c|c|c|}
\hline Antibacterial Method & Species of bacteria & $\begin{array}{l}\text { Concentration of } \\
\text { oil (\%) examined }\end{array}$ & MIC $\mu \mathrm{g} / \mathrm{ml}$ & size mm & OD reduction & Reference \\
\hline \multirow[t]{2}{*}{ Disk-diffusion } & E. coli & 100 & & 15.4 & & Mahmood et al., 2008 \\
\hline & S. aureus & 100 & & 41.5 & & \\
\hline \multirow[t]{2}{*}{ Disk-diffusion } & E. coli & 100 & & 12 & & Helen et al., 2011 \\
\hline & $P$. aeruginosa $S$. & 100 & & 12 & & \\
\hline \multirow[t]{3}{*}{ Optical density reduction } & E. coli & 10 & & & 0.40 & Mishra and Mishra, 2011 \\
\hline & P. aeruginosa & 10 & & & 0.71 & \\
\hline & S. aureus & 10 & & & 0.62 & \\
\hline \multirow[t]{3}{*}{ Broth micro-dilution method } & E. coli & $0.5-4.5$ & 2.25 & & & This study \\
\hline & $P$. aeruginosa & $0.5-4.5$ & $>4.5$ & & & \\
\hline & S. aureus & $0.5-4.5$ & 2.5 & & & \\
\hline
\end{tabular}


Concentrations below $20 \mathrm{mg} / \mathrm{ml}$ had no effect on the cell viability.

\section{Comparison of Tulsi Volatile Compounds from Species Cultivated in Different Geographical Locations}

Although the major types of volatile compounds identified by this study (monoterpenes and sesquiterpenes) were also identified in other studies, there are important quantitative differences in the distribution of these compounds in plants grown in other geographical areas. In previous reviews, Tulsi essential oil was generally reported to contain volatile compounds comprising monoterpenes such as linalool, estragol, eugenol, and small quantities of methyl cinnamate, cineole, tannins, camphor, and other compounds (Prakash and Gupta, 2005). However, the quantity of the volatile compounds identified and the major and minor compounds varied in different studies.

Also in agreement with the present study, an exhaustive survey by Singh et al. (2010) showed that extracts from fresh leaves and stems of Tulsi contain a number of sesquiterpenes and monoterpenes such as $\alpha$-elemene, bornyl acetate, $\alpha$ - and $\beta$-pinenes, campesterol, and camphene, but the composition and amounts of the various compounds differed from those reported here. These differences could relate to the geographical origin of plant cultivars and environmental factors, which significantly influence the volatile composition and percentage, or to the method of extraction and analysis. Table 4 displays examples of the major volatile compounds present in the essential oil extracted from Tulsi plants grown in different locations indicating that environmental factors strongly influence its chemical composition. Therefore, it was strongly suggested to analyze the composition of the volatile compounds of the essential oil before examining the oil for antimicrobial or other activity (Kalemba and Kunicka, 2003).

\section{Bioactive Volatile Compounds Present in Tulsi}

Camphor was the most abundant volatile compound present in essential oil (31.52\%), leaves $(24.15 \%)$, and flower spikes (22.55\%) of the Australian-grown Tulsi (Table 2). Eucalyptol was the second most abundant volatile compound present in both essential oil and the leaves (18.85 and $13.47 \%$, respectively). Camphor and eucalyptol are major components of the essential oils of three Greek Achillea species (A. taygetea, 26.6\%; A. holosericea, 20.9\%; A. fraasii, 16.3\%). Furthermore, eucalyptol is the major constituent of the essential oil of $A$. taygetea and $A$. fraasii (25.7 and $11.9 \%$, respectively), but was detected only in trace amounts $(0.7 \%)$ in the oil of $A$. holosericea. The antimicrobial activity of these essential oils was assessed against six bacterial species; S. aureus, S. epidermidis, E. coli, Enterobacter cloacae, Klebsiella pneumoniae, and $P$. aeruginosa using the broth dilution technique. The oils of $A$. taygetea and $A$. fraasii showed

TABLE 4 | Examples of the major volatile compounds present in the essential oil extracted from Tulsi plants grown in different location.

\begin{tabular}{|c|c|c|c|c|}
\hline Geographical location & Source of essential oil & Major compounds & Concentration \% & Reference \\
\hline \multirow[t]{2}{*}{ India } & Leaves & Methyl eugenol & 32.9 & Helen et al., 2011 \\
\hline & & cyclooctene & 17.6 & \\
\hline \multirow[t]{3}{*}{ India } & Leaves & Eugenol, & 27.4 & Naquvi et al., 2012 \\
\hline & & bornyl acetate & 14.5 & \\
\hline & & camphor & 9.0 & \\
\hline \multirow[t]{2}{*}{ India } & Leaves, inflorescence, leaves and inflorescence & Methyl eugenol, & $75.3,65.2,72.5$ & Kothari et al., 2005 \\
\hline & & beta caryophyllene & $6.4,12.0,5.5$ & \\
\hline \multirow[t]{2}{*}{ Brazil } & Leaves, inflorescence & Eugenol & $79.0,17.6$ & Machado et al., 1999 \\
\hline & & caryophyllene & $9.8,24.5$ & \\
\hline \multirow[t]{3}{*}{ Australia } & Leaves & Methyl chavicol & 87 & Brophy et al., 1993 \\
\hline & & camphor & 4 & \\
\hline & & beta caryophyllene & 5 & \\
\hline \multirow[t]{3}{*}{ Cuba } & Leaves and inflorescence & Eugenol & 34.3 & Pino et al., 1998 \\
\hline & & elemene & 18.0 & \\
\hline & & beta caryophyllene & 23.1 & \\
\hline \multirow[t]{5}{*}{ Germany } & Leaves & Eugenol & 38.2 & Laakso et al., 1990 \\
\hline & & methyl chavicol & 14.4 & \\
\hline & & eucalyptol & 11.0 & \\
\hline & & beta bisabolene & 9.4 & \\
\hline & & alpha bisabolene & 7.5 & \\
\hline \multirow[t]{6}{*}{ Australia (Victoria) } & Leaves and inflorescence & Camphor & 31.5 & This study \\
\hline & & eucalyptol & 18.9 & \\
\hline & & eugenol & 13.8 & \\
\hline & & alpha bisabolene & 3.8 & \\
\hline & & beta bisabolene & 2.2 & \\
\hline & & beta caryophyllene & 1.2 & \\
\hline
\end{tabular}


strong to moderate activity against all six bacterial species, but the oil of $A$. holosericea was shown to have no antibacterial activity. In the same study, camphor was shown to be more effective than eucalyptol against the same bacterial species. It was proposed that the antibacterial properties of the essential oils of $A$. taygetea and A. fraasii are associated with their high content of camphor and eucalyptol (Magiatis et al., 2002). Both camphor and eucalyptol, identified as the abundant volatile compounds present in the essential oils of five taxa of Sideritis from Greece, were shown to possess some antimicrobial activity (Aligiannis et al., 2001). Moreover, camphor and eucalyptol standards obtained from Merck showed activity against E. coli and S. aureus, Bacillus cereus, $P$. aeruginosa, with camphor being more effective than eucalyptol (Mahboubi and Kazempour, 2009). Since both these compounds were identified as major components of Australiangrown Tulsi, we suggest that these substances may be responsible for the antimicrobial activity identified by this study.

The third most abundant compound identified in the present study, eugenol, formed 13.8, 23.7, and $7.5 \%$ of the total volatile compounds in the essential oil, leaves and inflorescence, respectively. Eugenol was also the main constituent of the Tulsi leaves grown in India, Brazil, Bangladesh, Cuba, and Germany (Table 4). In several reviews (Prakash and Gupta, 2005; Pattanayak et al., 2010; Singh et al., 2010) the therapeutic value of Tulsi leaves was attributed mainly to eugenol. Eugenol was identified as a major component (67\%) of the essential oil of Ocimum gratissimum, and may be responsible for the antibacterial activity of that oil.

Another compound, $\beta$-caryophyllene, which comprised 4.9, 1.5 , and $1.2 \%$ of volatile compounds in inflorescence, leaves and oil, respectively, of Australian-grown Tulsi, is a sesquiterpene which is widely distributed in essential oils of various plants. $\beta$ - caryophyllene has been used for fragrance in cosmetics and as a food additive. $\beta$ - caryophyllene also possesses antimicrobial activity (Alma et al., 2003; Legault and Pichette, 2007; Xiao-Yu et al., 2012). For example, Alma et al. (2003) examined the antimicrobial activities of essential oils extracted from the leaves of Origanum syriacum, which contained $\beta$-caryophyllene at a concentration of $12.6 \%$. Using the agar-disk diffusion method, the oil was shown to have activity against $S$. aureus, E. coli, and $P$. aeruginosa. These findings suggest that $\beta$ - caryophyllene may have contributed to the antimicrobial activity against the same three species of bacteria that was demonstrated in the present study.

Tulsi essential oil contains a valuable source of bioactive compounds such as camphor, eucalyptol, eugenol, alpha bisabolene, beta bisabolene, and beta caryophyllene. These compounds are proposed to be responsible for the antimicrobial properties of the leaf extracts. Further characterisation of individual compounds and their combinations will shed light on the most effective combination that can be used to treat skin infections. Such study could also include gene expression assays to determine the mechanism of action of these bioactive compounds. Once convincing evidence is obtained, formulations such as creams and gels could be derived from the Tulsi leaf extract, essential oil, or its bioactive compounds and tested for efficacy in treating skin infections. Considering Tulsi has been used for over 1000 years, such formulations are likely to be safer and readily accepted by consumers.

\section{CONCLUSION}

In summary, the essential oil extracted from Ocimum tenuiflorum showed antimicrobial activity against $S$. aureus (including MRSA) and E. coli, but was less active against $P$. aeruginosa. Responses of $P$. aeruginosa to antimicrobial compounds was recently reviewed (Morita et al., 2014) and some compounds were found to interact with RND efflux pumps of the bacteria (Dreier and Ruggerone, 2015). In some other studies, $P$. aeruginosa has been shown to be more resistant than other most Gram negative bacteria to the action of the essential oils (Prabuseenivasan et al., 2006; Mahmood et al., 2008), but others have shown either increased sensitivity (Mishra and Mishra, 2011) or no difference in activity (Helen et al., 2011). A detailed analysis of the volatile compounds found in the essential oil and extracts from leaves and inflorescence revealed 54 different components that varied in presence and concentration in the three different sample types. A review of the literature suggested that the main components responsible for the antimicrobial activity of Tulsi oil were likely to be camphor, eucalyptol, and eugenol. $\beta$-caryophyllene may also have contributed to the antimicrobial activity of the oil but was present in smaller amounts. Since $S$. aureus, including MRSA, P. aeruginosa, and E. coli are major pathogens causing SSTIs, Tulsi essential oil could be a valuable topical antimicrobial agent for management of skin infections caused by these organisms or as a wound dressing to prevent infection. Early treatment or preventative measures may halt progression to more serious infection requiring systematic antibiotic therapy, and reduce the risk of development of resistance to valuable antibiotics.

\section{AUTHOR CONTRIBUTIONS}

EP and NM conceptualized the project. HY performed microbiological testing. EP, HY, NM, and MD analyzed the data and wrote the manuscript.

\section{FUNDING}

HY is grateful to the Saudi Arabian government for the award of a Ph.D. scholarship.

\section{ACKNOWLEDGMENTS}

The authors would like to gratefully acknowledge Paul D. Morrison for technical assistance. 


\section{REFERENCES}

Aligiannis, N., Kalpoutzakis, E., Chinou, I., Mitakou, S., Gikas, E., and Tsarbopoulos, A. (2001). Composition and antimicrobial activity of the essential oils of five taxa of Sideritis from Greece. J. Agric. Food. Chem. 49, 811-815. doi: 10.1021/jf001018w

Alma, M. H., Mavi, A., Yildirim, A., Digrak, M., and Hirata, T. (2003). Screening chemical composition and in vitro antioxidant and antimicrobial activities of the essential oils from Origanum syriacum L. growing in Turkey. Biol. Pharm. Bull. 26, 1725-1729. doi: 10.1248/bpb.26.1725

Brophy, J. J., Goldsack, R. J., and Clarkson, J. R. (1993). The essential oil of Ocimum tenuiflorum L.(Lamiaceae) growing in Northern Australia. J. Essent. Oil. Res. 5, 459-461. doi: 10.1080/10412905.1993.9698260

Burt, S. (2004). Essential oils: their antibacterial properties and potential applications in foods-a review. Int. J. Food. Microbil. 94, 223-253. doi: 10.1016/j.ijfoodmicro.2004.03.022

Chang, J. D., Mantri, N., Sun, B., Jiang, L., Chen, P., Jiang, B., et al. (2016). Effects of elevated $\mathrm{CO} 2$ and temperature on Gynostemma pentaphyllum physiology and bioactive compounds. J. Plant Physiol. 19, 41-52. doi: 10.1016/j.jplph.2016.02.020

Clinical and Laboratory Standards Institute (2012). Methods for Dilution Antimicrobial Susceptibility Tests for Bacteria That Grow Aerobically, Approved standard M7-A9, 9th Edn. Wayne, PA: Clinical and Laboratory Standards Institute.

Cutler, H. G., and Cutler, S. J. (1999). Biologically Active Natural Products: Agrochemicals. Boca Raton, FL: CRC Press.

Da Porto, C., and Decorti, D. (2008). Analysis of the volatile compounds of flowers and essential oils from Lavandula angustifolia cultivated in Northeastern Italy by headspace solid-phase microextraction coupled to gas chromatographymass spectrometry. Planta Med. 74, 182-187. doi: 10.1055/s-20081034295

Dreier, J., and Ruggerone, P. (2015). Interaction of antibacterial compounds with RND efflux pumps in Pseudomonas aeruginosa. Front. Microbiol. 6:660. doi: 10.3389/fmicb.2015.00660

Dryden, M. S. (2009). Skin and soft tissue infection: microbiology and epidemiology. Int. J. Antimicrob. Agents 34, S2-S7. doi: 10.1016/S09248579(09)70541-2

Dryden, M. S. (2010). Complicated skin and soft tissue infection. J. Antimicrob. Chemother. 65(Suppl. 3), iii35-iii44. doi: 10.1093/jac/dkq302

Eron, L., Lipsky, B., Low, D., Nathwani, D., Tice, A., and Volturo, G. (2003). Expert panel on managing skin and soft tissue infections. Managing skin and soft tissue infections: expert panel recommendations on key decision points. J. Antimicrob. Chemother. 52, i3-i17. doi: 10.1093/jac/dkg466

Helen, M. P., Raju, V., Gomathy, S. K., Nizzy, S. K., and Sree, S. J. (2011). Essential oil analysis in Ocimum sps. Herbal Technol. Industry 8, 12-15.

Honório, V. G., Bezerra, J., Souza, G. T., Carvalho, R. J., Gomes-Neto, N. J., Figueiredo, R. C., et al. (2015). Inhibition of Staphylococcus aureus cocktail using the synergies of oregano and rosemary essential oils or carvacrol and 1,8-cineole. Front. Microbiol. 6:1223. doi: 10.3389/fmicb.2015. 01223

Jiang, B., Mantri, N., Hu, Y., Lu, J., Jiang, W., and Lu, H. (2015). Evaluation of bioactive compounds of black mulberry juice after thermal, microwave, ultrasonic processing and storage at different temperatures. Food Sci. Technol. Int. 21, 392-399. doi: 10.1177/1082013214539153

Jiang, W., Jiang, B., Mantri, N., Wu, Z., Mao, L., Lu, H., et al. (2014). Comparative ecophysiological analysis of photosynthesis, biomass allocation, polysaccharide and alkaloid content in three Dendrobium candidum cultivars. Plant Omics J. 7, 117-122.

Kalemba, D., and Kunicka, A. (2003). Antibacterial and antifungal properties of essential oils. Curr. Med. Chem. 10, 813-829. doi: 10.2174/09298670334 57719

Kothari, S., Bhattacharya, A., Ramesh, S., Garg, S., and Khanuja, S. (2005). Volatile constituents in oil from different plant parts of methyl eugenol-rich Ocimum tenuiflorum Lf (syn. O. sanctum L.) grown in South India. J. Essent. Oil Res. 17, 656-658. doi: 10.1080/10412905.2005.9699025

Laakso, I., Seppänen-Laakso, T., Herrmann-Wolf, B., Kühnel, N., and Knobloch, K. (1990). Constituents of the essential oil from the holy basil or tulsi plant, Ocimum sanctum. Planta. Med. 56:527. doi: 10.1055/s-2006-961084
Legault, J., and Pichette, A. (2007). Potentiating effect of beta-caryophyllene on anticancer activity of alpha-humulene, isocaryophyllene and paclitaxel. J. Pharm. Pharmacol. 59, 1643-1647. doi: 10.1211/jpp.59.12.0005

Machado, M. I. L., De Vasconcelos Silva, M. G., Matos, F. J. A., Craveiro, A. A., and Alencar, J. W. (1999). Volatile constituents from leaves and inflorescence oil of Ocimum tenuiflorum L. f.(syn. O. sanctum L.) grown in Northeastern Brazil. J. Essent. Oil Res. 11, 324-326. doi: 10.1080/10412905.1999.9701145

Magiatis, P., Skaltsounis, A.-L., Chinou, I., and Haroutounian, S. A. (2002). Chemical composition and in-vitro antimicrobial activity of the essential oils of three Greek Achillea species. Z. Naturforsch. C 57, 287-290. doi: 10.1515/znc2002-3-415

Mahboubi, M., and Kazempour, N. (2009). The antimicrobial activity of essential oil from Perovskia abrotanoides karel and its main components. Indian J. Pharm. Sci. 71, 343. doi: 10.4103/0250-474X.56016

Mahmood, K., Yaqoob, U., and Bajwa, R. (2008). Antibacterial activity of essential oil of Ocimum sanctum L. Mycopath 6, 63-65.

Mandave, P., Pawar, P., Ranjekar, P., Mantri, N., and Kuvalekar, A. (2014). Comprehensive evaluation of in vitro antioxidant activity, total phenols and chemical profiles of two commercially important strawberry varieties. Sci. Hortic. 172, 124-134. doi: 10.1016/j.scienta.2014.03.002

Mantri, N., Olarte, A., Li, C. G., Xue, C., and Pang, E. C. K. (2012). Fingerprinting the asterid species using subtracted diversity array reveals novel species-specific sequences. PLoS ONE 7:e34873. doi: 10.1371/journal.pone.00 34873

Mathela, C. S. (1991). "Allelochemicals in medicinal and aromatic plants," in Allelopathy in Agriculture and Forestry, eds S. S. Narwal and P. Tauro (Jodhper: Scientific Publishers), 213-228.

Medina-Holguín, A. L., Micheletto, S., Holguín, F. O., Rodriguez, J., O’connell, M. A., and Martin, C. (2007). Environmental influences on essential oils in roots of Anemopsis californica. HortScience 42, 1578-1583.

Mishra, P., and Mishra, S. (2011). Study of antibacterial activity of Ocimum sanctum extract against Gram positive and Gram negative bacteria. Am. J. Food Technol. 6, 336-341. doi: 10.3923/ajft.2011.336.341

Morita, Y., Tomida, J., and Kawamura, Y. (2014). Responses of Pseudomonas aeruginosa to antimicrobials. Front. Microbiol. 4:422. doi: 10.3389/fmicb.2013.00422

Naquvi, K. J., Dohare, S. L., Shuaib, M., and Ahmad, M. I. (2012). Chemical composition of volatile oil of Ocimum sanctum Linn. Int. J. Biomed. Adv. Res. 3, 129-131. doi: 10.7439/ijbar.v3i2.290

Niu, L., Mantri, N., Li, C. G., Xue, C., and Pang, E. C. K. (2011). Arraybased techniques for fingerprinting herbal plants. BMC Chin. Med. 6:18. doi: 10.1186/1749-8546-6-18

Olarte, A., Mantri, N., Nugent, G., Li, C. G., Xue, C., and Pang, E. C. K. (2013). A gDNA microarray for genotyping Salvia species. Mol. Biotechnol. 54, 770-783. doi: 10.1007/s12033-012-9625-5

Pattanayak, P., Behera, P., Das, D., and Panda, S. K. (2010). Ocimum sanctum Linn. A reservoir plant for therapeutic applications: an overview. Pharmacogn. Rev. 4:95. doi: 10.4103/0973-7847.65323

Pino, J. A., Rosado, A., Rodriguez, M., and Garcia, D. (1998). Composition of the essential oil of Ocimum tenuiflorum L. grown in Cuba. J. Essent. Oil Res. 10, 437-438. doi: 10.1080/10412905.1998

Poole, K. (2011). Pseudomonas aeruginosa: resistance to the max. Front. Microbiol. 2:65. doi: 10.3389/fmicb.2011.00065

Prabuseenivasan, S., Jayakumar, M., and Ignacimuthu, S. (2006). In vitro antibacterial activity of some plant essential oils. BMC Complement. Altern. Med. 6:39. doi: 10.1186/1472-6882-6-39

Prakash, P., and Gupta, N. (2005). Therapeutic uses of Ocimum sanctum Linn (Tulsi) with a note on eugenol and its pharmacological actions: a short review. Indian J. Physiol. Pharmacol. 49, 125-131.

Singh, V., Amdekar, S., and Verma, O. (2010). Ocimum Sanctum (tulsi): Biopharmacological Activities. WebmedCentral Pharmacol. 1:WMC001046. doi: 10.9754/journal.wmc.2010.001046

Sun, X., Mantri, N., Ge, J., Du, Y., Lu, J., Jiang, W., et al. (2014). Inhibition of plant pathogens in vitro and in vivo with essential oil and organic extracts of Torreya grandis 'Merrilli' aril. Plant Omics J. 7, 337-344.

Wiegand, I., Hilpert, K., and Hancock, R. E. (2008). Agar and broth dilution methods to determine the minimal inhibitory concentration (MIC) of antimicrobial substances. Nat. Protoc. 3, 163-175. doi: 10.1038/nprot.2007.521 
Wu, Z. W., Jiang, W., Mantri, N., Bao, X. Q., Chen, S. L., and Tao, Z. M. (2016). Characterizing diversity based on nutritional and bioactive compositions of yam germplasm (Dioscorea spp.) commonly cultivated in China. J. Food Drug Anal. 24, 367-375. doi: 10.1016/j.jfda.2015.12.003

Xiao-Yu, L., Xu-Bing, C., and Guang-Yong, C. (2012). Research progress in bioactivity and synthesis of $\beta$-caryophyllene and its derivatives. Chem. Ind. For. Prod. 32, 104-110.

Yamani, H., Mantri, N., Morrison, P. D., and Pang, E. (2014). Analysis of the volatile organic compounds from leaves, flower spikes, and nectar of Australian grown Agastache rugosa. BMC Complement. Altern. Med. 14:495. doi: 10.1186/14726882-14-495
Conflict of Interest Statement: The authors declare that the research was conducted in the absence of any commercial or financial relationships that could be construed as a potential conflict of interest.

Copyright (c) 2016 Yamani, Pang, Mantri and Deighton. This is an open-access article distributed under the terms of the Creative Commons Attribution License (CC BY). The use, distribution or reproduction in other forums is permitted, provided the original author(s) or licensor are credited and that the original publication in this journal is cited, in accordance with accepted academic practice. No use, distribution or reproduction is permitted which does not comply with these terms. 